See Article page 636

\section{Commentary: Silent brain lesions add noise to the on- versus off-pump coronary artery bypass grafting debate}

\author{
William C. Frankel, BS, ${ }^{a}$ and Tom C. Nguyen, MD $^{b}$
}

The debate between on-pump (ONCABG) and off-pump coronary artery bypass grafting (OPCABG) has waged on for more than 30 years. Early proponents favored OPCABG based on the hypothesis that removing cardiopulmonary bypass (CPB) from the operation would mitigate perioperative complications such as stroke. However, after 3 large randomized controlled trials (Randomized On/Off Bypass [ROOBY], Coronary Artery Bypass Surgery Off or On Pump Revascularization Study [CORONARY], and German Off Pump Coronary Artery Bypass Grafting in Elderly Patients [GOPCABE]) failed to show a difference in stroke rate between ONCABG and OPCABG,${ }^{1-3}$ the pendulum swung back in favor of ONCABG. Recently, the debate has been reignited after the SYNTAX (Synergy between Percutaneous Coronary Intervention with Taxus and Cardiac Surgery) trial revealed a lower risk of stroke after percutaneous coronary intervention compared with CABG surgery. ${ }^{4}$ Consequently, cardiac surgeons are entrenched in an arms race to develop techniques that reduce the risk of neurologic complications after $\mathrm{CABG}$, given that these complications are of paramount importance to patients who require coronary revascularization.

It is in this context that we read with interest the paper by Tachibana and colleagues ${ }^{5}$ in this issue of the Journal in which the authors describe the incidence and impact of "silent" brain lesions after CABG. The authors report their experience with 104 patients who underwent elective and

\footnotetext{
From the ${ }^{a}$ Baylor College of Medicine and ${ }^{b}$ Department of Cardiothoracic and Vascular Surgery, University of Texas Health Science Center, McGovern Medical School, Houston, Tex.

Disclosures: The authors have nothing to disclose with regard to commercial support. Received for publication Nov 4, 2019; revisions received Nov 4, 2019; accepted for publication Nov 4, 2019; available ahead of print Nov 27, 2019.

Address for reprints: Tom C. Nguyen, MD, Department of Cardiothoracic and Vascular Surgery, University of Texas Health Science Center, McGovern Medical School, 6400 Fannin St, Suite 2850, Houston, TX 77030 (E-mail: tom.c.nguyen@ gmail.com).

J Thorac Cardiovasc Surg 2021;161:645-6

0022-5223/\$36.00

Copyright (C) 2019 by The American Association for Thoracic Surgery

https://doi.org/10.1016/j.jtcvs.2019.11.024
}

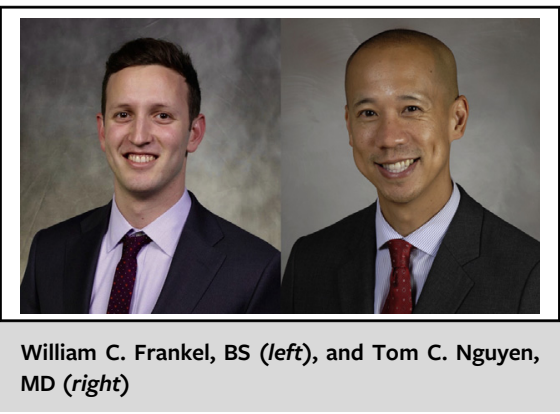

CENTRAL MESSAGE

New brain lesions detected on

MRI occur in approximately $20 \%$

of patients after CABG and may

be associated with postoperative

cognitive dysfunction.

isolated first-time $\mathrm{CABG}$ over a 2-year study period. These patients were selected to undergo ONCABG $(n=39)$ or OPCABG $(n=65)$, with or without aortic clamping, based on surgeon evaluation. All patients underwent preoperative and postoperative (within 2 weeks after surgery) magnetic resonance imaging (MRI) of the brain to identify the presence of new brain lesions. The incidence of new brain lesions detected on MRI was $20 \%$ overall; $33 \%$ (13/39), $12 \%(8 / 65)$, and $16 \%(3 / 19)$ of patients in the ONCABG, OPCABG, and aortic no-touch groups, respectively, developed new brain lesions after surgery.

The authors are to be congratulated for their timely and important study along with several noteworthy findings of relevance to the continued ONCABG versus OPCABG debate. The authors found that postoperative cognitive dysfunction (POCD) occurred more often in patients with multiple or large lesions. Although these patients were not at increased risk of mortality or major complications, they were more likely to experience a decline in functional status after surgery. In contrast to the ROOBY, CORONARY, and GOPCABE trials, CPB appeared to be an important risk factor for new brain lesions in this study. This association is supported by a large single-center study along with 2 recent meta-analyses that showed a significantly lower rate of stroke in patients who underwent OPCABG compared with ONCABG ${ }^{6-8}$ Surprisingly, however, new brain lesions were also detected in $16 \%$ (3/19) of patients in the aortic no-touch OPCABG group. Although no randomized trials have directly compared ONCABG with aortic no-touch OPCABG, several single-center studies 
along with a recent meta-analysis have shown that the aortic no-touch technique reproducibly reduces the rate of stroke to $\leq 1 \%{ }^{9-11}$ comparing favorably with the $0.6 \%$ rate associated with percutaneous coronary intervention in the SYNTAX trial. ${ }^{4}$ Taken together, these findings suggest that although the aortic no-touch technique may be associated with lower rates of overt stroke, new brain lesions are still common using this technique, which represents an enigma. In turn, these findings may indicate that the aortic no-touch technique cannot completely mitigate the risk of postoperative neurologic complications previously attributed to CPB and aortic manipulation.

The lack of randomization, especially in the context of the inherent subjectivity in assessment of POCD, is an important limitation to this study. Furthermore, the authors do not comment on whether the radiologists or the individuals administering the neurocognitive assessments were blinded to the procedure being performed. Only one metric - the Katz Activities of Daily Living score-was lower in patients with new brain lesions after CABG. This is noteworthy, given that activities of daily living are multifactorial and therefore a "dirty" surrogate for neurologic decline. The authors also failed to report the total number of patients in each group who experienced POCD, making it impossible to draw conclusions about the relative incidence of POCD between techniques. Taken together, these limitations leave us with more questions than answers in terms of the relative incidence of clinically meaningful lesions that persist after the early postoperative period for these techniques.

This study is an important addition to the literature insofar as it reveals that although the absolute risk of stroke after CABG is low, new brain lesions detected by MRI appear to be relatively common for both ONCABG and OPCABG groups. Whether these lesions lead to significant neurologic sequelae, that is, whether they are truly "silent" or not, remains to be fully elucidated but certainly adds some noise to the ONCABG versus OPCABG debates. It's possible these lesions could be the canary in the coal mine with respect to long-term cognitive and functional outcomes after CABG. Thus, this topic warrants further investigation from large, prospective studies with more detailed follow-up and more objective means of neurocognitive assessment. If we are to continue to offer CABG as a safe and durable option for coronary revascularization, further innovation in neuroprotective techniques for CABG must be aggressively pursued.

\section{References}

1. Shroyer AL, Grover FL, Hattler B, Collins JF, McDonald GO, Kozora E, et al. On-pump versus off-pump coronary-artery bypass surgery. $N$ Engl J Med. 2009;361:1827-37.

2. Lamy A, Devereaux PJ, Prabhakaran D, Taggart DP, Hu S, Paolasso E, et al. Off-pump or on-pump coronary-artery bypass grafting at 30 days. $N$ Engl $J$ Med. 2012;366:1489-97.

3. Diegeler A, Börgermann J, Kappert U, Breuer M, Böning A, Ursulescu A, et al. Off-pump versus on-pump coronary-artery bypass grafting in elderly patients. N Engl J Med. 2013;368:1189-98.

4. Serruvs PW, Morice MC, Kappetein AP, Colombo A, Holmes DR, Mack MJ, et al. Percutaneous coronary intervention versus coronaryartery bypass grafting for severe coronary artery disease. $N$ Engl $J$ Med. 2009;360:961-72

5. Tachibana H, Hiraoka A, Saito K, Naito Y, Chikazawa G, Tamura K, et al. Incidence and impact of silent brain lesions after coronary artery bypass grafting. J Thorac Cardiovasc Surg. 2021;161:636-44.

6. Lattouf OM, Thourani VH, Kilgo PD, Halkos ME, Baio KT, Myung R, et al. Influence of on-pump versus off-pump techniques and completeness of revascularization on long-term survival after coronary artery bypass. Ann Thorac Surg. 2008;86:797-805.

7. Kuss O, Von Salviati B, Börgermann J. Off-pump versus on-pump coronary artery bypass grafting: a systematic review and meta-analysis of propensity score analyses. J Thorac Cardiovasc Surg. 2010;140:829-35.

8. Kowalewski M, Pawliszak W, Malvindi PG, Bokszanski MP, Perlinski D, Raffa GM, et al. Off-pump coronary artery bypass grafting improves short-term outcomes in high-risk patients compared with on-pump coronary artery bypass grafting: Meta-analysis. J Thorac Cardiovasc Surg. 2016;151: 60-77.

9. Emmert MY, Seifert B, Wilhelm M, Grünenfelder J, Falk V, Salzberg SP. Aortic no-touch technique makes the difference in off-pump coronary artery bypass grafting. J Thorac Cardiovasc Surg. 2011;142:1499-506.

10. Moss E, Puskas JD, Thourani VH, Kilgo P, Chen EP, Leshnower BG, et al. Avoiding aortic clamping during coronary artery bypass grafting reduces postoperative stroke. J Thorac Cardiovasc Surg. 2015;149:175-80.

11. Zhao DF, Edelman JJ, Seco M, Bannon PG, Wilson MK, Byrom MJ, et al. Coronary artery bypass grafting with and without manipulation of the ascending aorta: A network meta-analysis. J Am Coll Cardiol. 2017;69:924-36. 